\title{
Grinding of transformation-toughened mixed oxide ceramic
}

\author{
Berend Denkena $^{1} \cdot$ Alexander Krödel $^{1} \cdot$ Andi Wippermann $^{1} \cdot$ Philipp Wolters $^{1}$
}

Received: 30 March 2020 / Accepted: 6 July 2020 / Published online: 16 July 2020

(C) The Author(s) 2020

\begin{abstract}
During the manufacturing of ceramic components, grinding is an important manufacturing step. It influences the workpiece quality and the operational reliability. Thermomechanical loads during grinding can influence the lifetime and operational reliability of ceramics by modifying their bending strength and subsurface properties. Therefore, it is necessary to consider the influence of the grinding forces and mechanical loads on the strength of the ceramics in order to design a suitable grinding process. In this investigation, a quick-stop device is used to interrupt the grinding process of the newly developed mixed oxide ceramic SHYTZ (strontium hexaaluminate/yttria-toughened zirconia) and the market-established ceramic ATZ (alumina-toughened zirconia). Subsequently, an analysis of the occurring material removal phenomena, the number of active abrasive grains, and the real thermomechanical loads is carried out. It was found that the number of active grains and the material removal phenomena are influenced by the tool specifications. Besides that, the experimentally determined number of active grains was found to be up to 14 times higher than predicted by an analytical model given in literature. Consequently, the calculated single grain chip thickness was found to be up to $12.1 \%$ lower than analytically predicted. The investigation of the process forces and thermal loads showed up to 52\% higher loads for ATZ than for SHYTZ. The subsequent analysis of the resulting bending strength of the ceramics revealed a lower influence of the grinding process on the strength of SHYTZ than for ATZ. Furthermore, a correlation between the used tool bonding and the resulting thermomechanical loads, bending strength, and residual stresses could be observed.
\end{abstract}

Keywords Transformation-toughened mixed oxide ceramics · Grinding · Interruption of cut · Thermomechanical workpiece load · Bending strength

\begin{tabular}{ll}
\multicolumn{2}{l}{ Nomenclature } \\
$a$ & Thermal diffusivity \\
$a_{\mathrm{e}}$ & Depth of cut \\
$a_{\mathrm{p}}$ & Width of cut \\
$a_{\mathrm{s}}(\mathrm{t})$ & Time-dependent accelerating behavior \\
$A_{\mathrm{cu}}$ & Chip cross-sectional area \\
$A_{\mathrm{k}}$ & Contact area \\
$A_{\mathrm{KG}}$ & Grain contact area \\
$c_{\mathrm{p}}$ & Specific heat capacity \\
$C$ & Grain concentration \\
$E$ & Young's modulus \\
$F_{\mathrm{n}}^{\prime}$ & Specific normal force \\
$F_{\mathrm{nG}}$ & Grain normal force
\end{tabular}

Philipp Wolters

wolters@ifw.uni-hannover.de

1 Institute of Production Engineering and Machine Tools (IFW),

Leibniz Universität Hannover, An der Universität 2,

30823 Garbsen, Germany

$\begin{array}{ll}F_{\mathrm{t}}^{\prime} & \text { Specific tangential force } \\ F_{\mathrm{tG}} & \text { Grain tangential force } \\ h_{\mathrm{cu}} & \text { Single grain chip thickness } \\ K_{0} & \begin{array}{l}\text { Modified Bessel function of the second kind and } \\ \text { zeroth order }\end{array} \\ K_{1}, K_{2} & \text { Model constants } \\ K_{\mathrm{Ic}} & \text { Fracture toughness } \\ l_{\mathrm{g}} & \text { Geometric contact length } \\ l_{\mathrm{gG}} & \text { Grain contact length } \\ L & \text { Dimensionless half length of the heat source } \\ N_{\mathrm{GaktA}} & \text { Number of active grains } \\ N_{\mathrm{GV}} & \text { Abrasive grain density } \\ q_{\mathrm{w}} & \text { Heat flow } \\ q_{\mathrm{wG}} & \text { Heat flow of a single grain } \\ Q^{\prime}{ }_{\mathrm{w}} & \text { Specific material removal rate } \\ R_{\mathrm{G}} & \text { Grain radius } \\ R_{\mathrm{S}} & \text { Grinding wheel radius } \\ R_{\mathrm{W}} & \text { Heat distribution factor } \\ s_{\mathrm{div}} & \text { Distance between grain and sample } \\ s_{\mathrm{G}} & \text { Path covered by a grain }\end{array}$


$s_{\mathrm{G}, \mathrm{x}} \quad$ Path covered by a grain in $x$-direction

$s_{\mathrm{G}, \mathrm{y}} \quad$ Path covered by a grain in $y$-direction

$s_{\mathrm{S}} \quad$ Path covered by the sample

$S_{\mathrm{vc}} \quad$ Path covered due to cutting speed

$s_{\mathrm{vc}, \mathrm{x}} \quad$ Path covered due to cutting speed in $x$-direction

$s_{\mathrm{vc}, \mathrm{y}} \quad$ Path covered due to cutting speed in $y$-direction

$s_{\mathrm{vf}} \quad$ Path covered due to feed velocity

$s_{\mathrm{vf}, \mathrm{x}} \quad$ Path covered due to feed velocity in $x$-direction

$s_{\mathrm{vf}, \mathrm{y}} \quad$ Path covered due to feed direction in $y$-direction

$t \quad$ Time

$T(\mathrm{x}, \mathrm{z}) \quad$ Temperature at a specific place

$T_{\max } \quad$ Grinding temperature

$T_{\text {maxG }} \quad$ Grain contact temperature

$u \quad$ Dimensionless parameter

$v_{\mathrm{B}} \quad$ Bolt velocity

$v_{\text {brake }}$ Velocity of the brake

$v_{\mathrm{c}} \quad$ Cutting speed

$v_{\mathrm{ft}} \quad$ Feed velocity

$v_{\mathrm{s}} \quad$ Carriage velocity

$X \quad$ Dimensionless distance to the center of the heat source

$X_{\mathrm{m}} \quad$ Monoclinic phase content

$Z \quad$ Dimensionless depth under the workpiece surface

$\lambda \quad$ Thermal conductivity

$\sigma_{\text {ESP }} \quad$ Residual stresses

$\sigma_{\mathrm{f}} \quad$ Bending strength

$\varphi \quad$ Angular position of a grain

\section{Introduction}

Mixed oxide ceramics are used in a wide range of medical applications due to their mechanical properties and their biocompatibility $[1,2]$. The high strength and fracture toughness of zirconia-doped oxide ceramics are associated with the tetragonal-to-monoclinic phase transformation during crack propagation. To enable the phase transformation, stabilization of the metastable tetragonal phase through alloying with aliovalent ions is necessary. Due to this stabilization, the volume-increasing effect of the phase transformation only takes place when the ceramic is loaded [3, 4].

The high regulatory requirements and quality standards of medical products make it necessary to carry out a final finishing process step to reach the required surface quality and geometrical accuracy $[5,6]$. Due to high hardness, grinding is the most important machining process for the finishing of mixed oxide ceramics [7]. As a finishing process step, the grinding process defines not only the resulting quality of the workpiece but also its operational reliability [8]. Furthermore, it is a relevant cost factor that accounts for up to $41 \%$ of total production costs. The thermomechanical workpiece loads of the grinding process can modify the bending strength and the subsurface properties. This can lead to a reduction of the workpiece lifetime or operational reliability. Furthermore, these loads can lead to damages and strength reduction, which can prevent the usage of the workpiece in the intended application. It is important to design the grinding process properly, since up to $92 \%$ of the value creation have been done before the grinding takes place [8-15].

\subsection{State of the art}

In order to design a suitable grinding process, the influence of the grinding forces and the thermomechanical loads on the strength of the ceramics must be considered [16, 17]. The grinding forces result from the sum of the forces acting on the active cutting grains of the grinding tool $[16,18]$. The resulting friction converts the mechanical energy into heat and thus into a thermal load [18]. Therefore, the forces and contact conditions acting on the active grains during the grinding process determine thermal and mechanical loads. Moreover, the material removal mechanisms have an influence on the quality and strength of the ground workpiece [19-34]. In order to describe the correlation between process parameters, single grain chips, material properties, material removal mechanisms, and workpiece load, different models have been developed [11, 23, 35-39].

However, contact conditions and the load of the active grains during the process cannot be easily investigated. One possibility of the investigation is to use single diamond scratching tests [40-43]. A disadvantage of this method is the comparatively low scratching speed, which is often up to six orders of magnitudes lower than during grinding processes. However, lately developed single diamond scratching tests allow scratching speeds that are in the same order of magnitude as grinding processes [40]. However, it is not possible to investigate the influence of multiple grain engagements on material removal mechanisms with this method. A new method to specifically investigate those engagements is the interruption of cut, which allows to freeze the actual engagement process in the cutting zone [44]. An analysis of the resulting contact zone via scanning electron microscopy enables the investigation of the material removal phenomena and the number of active grains $N_{\text {GaktA }}$.

In order to realize an interruption of cut in grinding, quickstop devices have been used frequently in the past. Hereby, the cutting speed $v_{\mathrm{c}}$ is the critical factor to achieve reliable results. Because of this, the challenge in realizing an interruption of cut is the high relative speed between the grinding tool and workpiece of up to $50 \mathrm{~m} / \mathrm{s}$ [44-46]. Therefore, quick-stop devices have to accelerate the workpiece as quickly as possible. In this way, a minimum period of time in which there is a relative speed between the sample and grinding tool during the interruption can be ensured. The first investigations using quick-stop devices dealt with cutting processes like turning and milling due to the high cutting speeds in grinding [47]. 
Later on, publications investigated the interruption of grinding processes using a segment acceleration method. However, no systematic studies were carried out [48]. Recently developed quick-stop devices enable a reliable interruption of the grinding processes with cutting speeds of up to $35 \mathrm{~m} / \mathrm{s}$ [44, 45, 49, 50].

In this paper, the number of active grains and the occurring material removal phenomena are investigated for the grinding of two transformation-toughened mixed oxide ceramics. Furthermore, the thermomechanical loads as well as their influence on the bending strength of the workpiece are analyzed. The investigated ceramics are the newly developed mixed oxide ceramic SHYTZ (strontium hexaaluminate/yttriatoughened zirconia) and the market-established ceramic ATZ (alumnia-toughened zirconia).

\section{Materials and methods}

\subsection{Quick-stop device}

The experimental setup and the interruption process of the quick-stop device are displayed in Fig. 1. All components of the device are made of hardened tool steel to reduce unintended movements or deflections. The main parts of the device are the captive bolt pistol, the sliding carriage with the sample, a dovetail guidance, two brake devices, and a base plate, which is mounted on the machine bench of a Röders RFM 600 machine tool. A screw can be used to apply a preload to the carriage. The carriage is held by a shear pin during the grinding process to avoid any movement of the carriage before the interruption is started. This enables the interruption of grinding process with cutting speeds of up to $50 \mathrm{~m} / \mathrm{s}$. This means an increase of $43 \%$ of the cutting speed which can be interrupted with this device, compared with previously used devices [44, 45, 49, 50].

As a first step (Fig. 1a), a pre-grinding of the sample is carried out in order to create comparable conditions for the subsequent quick-stop experiments. After that, a metal cable is used to connect the automatic release unit with the infeed axis of the machine (Fig. 1b). While the grinding of the sample takes place, the movement of the infeed axis leads to tension on the metal cable and activates the automatic release unit. This triggers the bolt at the same position of the grinding wheel in every experiment regardless of the feed velocity $v_{\mathrm{f}}$. The impact of the bolt accelerates the carriage opposite to the direction of the feed velocity and thus out of the contact zone between the sample and grinding wheel into brake I (Fig. 1c). Measurements with a high-speed camera show that the carriage reaches a maximum speed of $66 \mathrm{~m} / \mathrm{s}$ due to this acceleration. Brake I consists of a technical high-density foam that is hold in place by a metal enclosure. The foam absorbs the kinetic energy of the carriage. To prevent the carriage from moving back into contact with the grinding wheel due to an elastic behavior of the foam, the spring-applied second brake (II) moves out when the carriage has left its initial position (Fig. 1d). Finally, the carriage stops between brake I and brake II at the end of the experiment (Fig. 1e).

The duration of the accelerating phase until sample and grinding tool are separated from each other is important for chip removal mechanisms. Therefore, an analytical error analysis model was developed. This model can be used to evaluate the period of time during which the tool remains in contact with the sample after the bolt hits the carriage. In this way, the influence of the contact period on the results of the interruption can be estimated. In Fig. 2, the relative movement between a grain of the grinding wheel and the sample is illustrated. The dependencies presented are utilized to create the basis of the error analysis model. The model is based on equations (1)-(6) [51].

$$
\begin{aligned}
& s_{G}(t)=\sqrt{s_{G, x}(t)^{2}+s_{v c, y}(t)^{2}} \\
& s_{v c, y}(t)=t \cdot v_{c} \cdot \cos \left(\varphi+\omega_{c} \cdot t\right) \\
& s_{G, x}(t)=t \cdot\left(v_{f t}+v_{c} \cdot \sin \left(\varphi+\omega_{c} \cdot t\right)\right) \\
& \omega_{c}=\frac{v_{c}}{R_{S}} \\
& s_{\text {div }}(t)=s_{S}-s_{G, x} \\
& s_{S}(t)=\frac{1}{2} \cdot a_{S}(t) \cdot t^{2}
\end{aligned}
$$

In the moment just before the interruption of cut $(t=0$ $\mathrm{ms}$ ), the grain is engaged in the material with the single grain chip thickness and moves with the cutting speed $v_{\mathrm{c}}$. Its position at the contact arc is described by the angle $\varphi$. After being hit by the bolt, the sample $\left(t^{\prime}\right)$ moves with a velocity $v_{\mathrm{S}}$, which depends on the time-dependent acceleration behavior $a_{\mathrm{S}}(\mathrm{t})$ of the slide. The process is successfully interrupted when a gap between the engaging partners exists. Thus, the distance between the grain and sample $s_{\text {div }}(\mathrm{t})$ must be greater than zero. In order to calculate this distance, it is necessary to calculate the movement of the sample and the tool resulting from the feed velocity $s_{\mathrm{vf}}$ and the cutting speed $s_{\mathrm{vc}}$. Together, they describe the distance the grain travels with respect to the specimen $\left(s_{\mathrm{G}}\right)$ (Eqs. (1)-(3)). In order to perform those calculations, the angular velocity must be determined, which can be done by using the cutting speed $v_{\mathrm{c}}$ and the grinding wheel radius $R_{\mathrm{S}}$ (Eq. (4)).

The subsequent error analysis shows that the movement distance of the grain until the interruption of the cut is completed is between $9 \mu \mathrm{m}\left(v_{\mathrm{c}}=10 \mathrm{~m} / \mathrm{s}, v_{\mathrm{ft}}=12,100 \mathrm{~mm} / \mathrm{min}, \varphi=\right.$ $\left.0^{\circ}\right)$ and $168 \mu \mathrm{m}\left(v_{\mathrm{c}}=50 \mathrm{~m} / \mathrm{s}, v_{\mathrm{ft}}=12,100 \mathrm{~mm} / \mathrm{min}, \varphi=0^{\circ}\right)$. Compared with the geometric contact length, this corresponds 
Fig. 1 a-e Structure and interruption process of the quickstop device
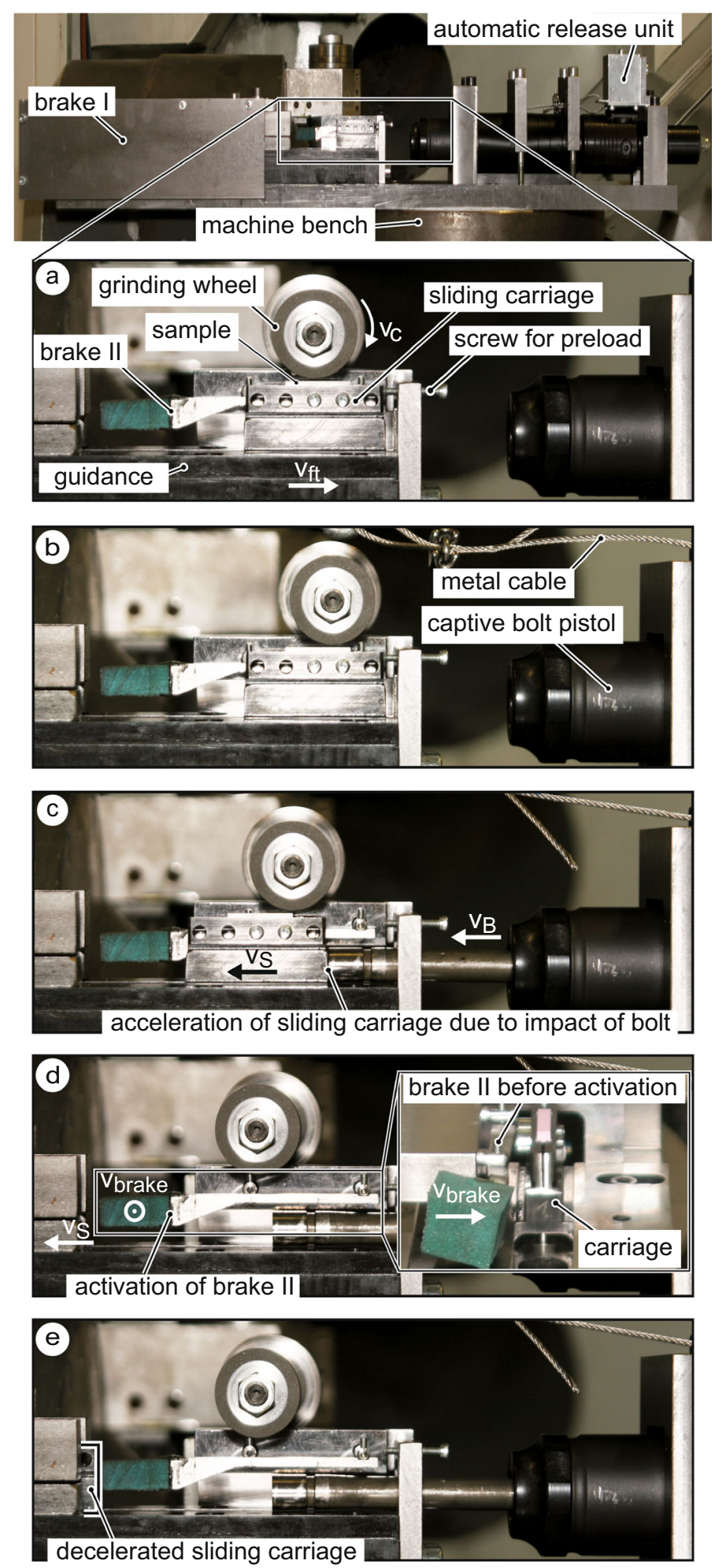
$50 \mathrm{~mm}$ 
to an error between $0.3 \%\left(a_{\mathrm{e}}=0.18 \mathrm{~mm}\right)$ and $15.3 \%\left(a_{\mathrm{e}}=0.02\right.$ $\mathrm{mm})$.

\subsection{Grinding experiments}

All grinding experiments were conducted as a face grinding operation in up-grinding kinematic. The parameter settings are summarized in Table 1. Each parameter is varied at five levels whereby each level is equidistantly distributed [51].

The investigation of the material removal mechanisms and the number of active grains is performed subsequently to the quick-stop experiments via scanning electron microscopy (SEM) (Zeiss EVO $60 \mathrm{VP}$ ). Since the material removal mechanisms at the beginning of the contact zone are most similar to the mechanisms of the surface generation, only the first third of the contact zone is evaluated for the analysis of the material separation mechanisms. The entire contact zone is analyzed for the investigation of the number of active grains. The set of grinding experiments is then repeated without interruption of cut to determine the mechanical and thermal loads of the grinding process. In this series of experiments, the grinding forces are measured via a Kistler 9257B 3-component piezoelectric dynamometer. Furthermore, residual stresses $\sigma_{\mathrm{ESP}}$ and the monoclinic phase content $X_{\mathrm{m}}$ are determined using a GE XRD 3003 ETA X-ray diffraction system with a 2-mmdiameter collimator and $\operatorname{CoK} \alpha$-radiation applying the $\sin ^{2} \psi$ method. The measuring error for the residual stresses is \pm $10 \mathrm{MPa}$ and less than three percent of the measured values for the monoclinic phase content. The bending strength $\sigma_{\mathrm{f}}$ is determined using a Zwick Type Z 1445 in a four-point bending test according to DIN EN 843-1. In these tests, the sample dimensions are $3 \times 4 \times 45 \mathrm{~mm}$. The distance between the lower bearings is $40 \mathrm{~mm}$ and $20 \mathrm{~mm}$ for the upper bearings. A feed speed of $3.5 \mathrm{~mm} / \mathrm{min}$ is applied in a fully air-
Table 1 Parameter settings of the grinding experiments

\begin{tabular}{llllll}
\hline Process variables & Levels \\
\hline Cutting speed $v_{\mathrm{c}}(\mathrm{m} / \mathrm{s})$ & 10 & 20 & 30 & 40 & 50 \\
Feed velocity $v_{\mathrm{f}}(\mathrm{mm} / \mathrm{min})$ & 100 & 3100 & 6100 & 9100 & 12,100 \\
Depth of cut $a_{\mathrm{e}}(\mathrm{mm})$ & 0.02 & 0.06 & 0.1 & 0.14 & 0.18 \\
Coolant & $5 \%$ oil in-water emulsion \\
\hline
\end{tabular}

conditioned room with a temperature of $24{ }^{\circ} \mathrm{C}$ and an air humidity of $50 \%$. The grinding temperatures are measured in process with four thermocouples with a diameter of $0.25 \mathrm{~mm}$ (Omega Type K). The resulting thermoelectric voltages are amplified with a measuring amplifier (Bedo Elektronik Type SAK12-660-100) and digitalized with an A-D converter (National Instruments Type BNC-2090). The measuring error of the temperature measurements is $0.4 \%$ of the measured value.

\subsection{Grinding tools}

Typical tools for the machining of ceramics are used in all investigations. To investigate the influence of the bond, three different bonding systems are used, which are shown in Table 2. All tools have a 1A1 geometry, a tool diameter of $30 \mathrm{~mm}$, and an abrasive layer width of $8 \mathrm{~mm}$. All tools use diamond with a grain size of $91 \mu \mathrm{m}$ as abrasives. The bonding systems differ in porosity and stiffness [51]. Therefore, their variation has a major influence on the resulting workpiece surface. For example, it is assumed that the chosen grinding tool is the most important factor for grinding-induced surface damages [13].
Fig. 2 Illustration of the relative movement between grain and sample during the interruption of cut

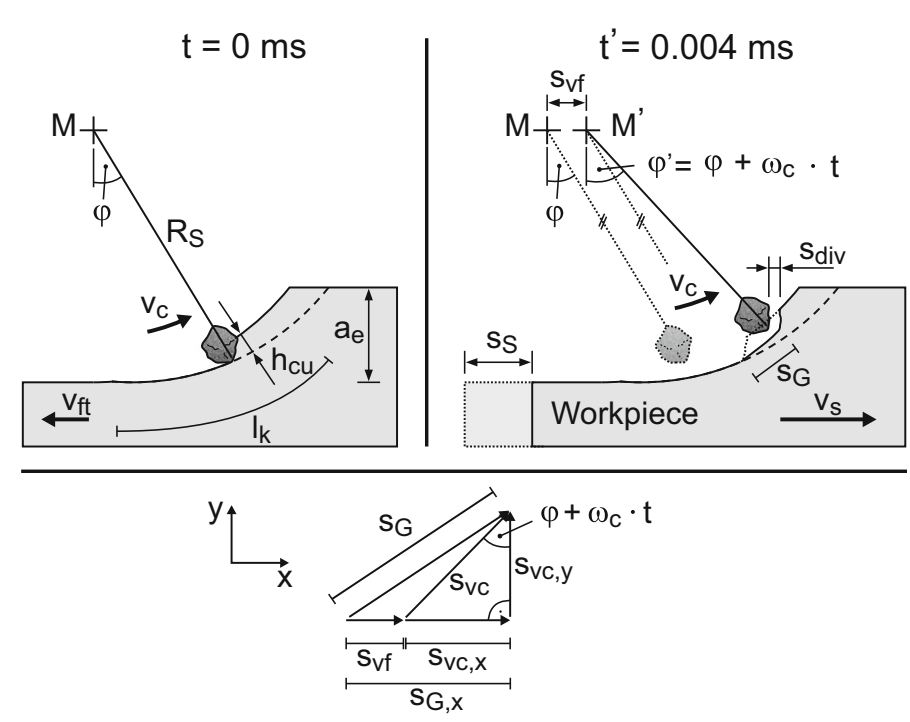


Table 2 Grinding tools

\begin{tabular}{llll}
\hline & Tool 1 & Tool 2 & Tool 3 \\
\hline Bond & Resin & Sintered metal & Galvanic \\
Abrasive & Diamond & Diamond & Diamond \\
Grain size & $91 \mu \mathrm{m}$ & $91 \mu \mathrm{m}$ & $91 \mu \mathrm{m}$ \\
Grain concentration & $\mathrm{C} 150$ & $\mathrm{C} 176$ & $\mathrm{C} 189$ \\
Pore volume & $0 \%$ & $32 \%$ & $0 \%$ \\
\hline
\end{tabular}

\subsection{Workpiece material}

Two workpiece materials are used in this study. Their composition and material properties are shown in Tables 3 and 4 . The first ceramic is the newly developed transformationtoughened mixed oxide ceramic SHYTZ (strontium hexaaluminate/yttria-toughened zirconia) $[52,53]$. Table 4 shows that this ceramic has a very high bending strength $\sigma_{\mathrm{f}}$ compared with the second ceramic combined with a high fracture toughness $K_{\mathrm{Ic}}$. The second ceramic is the marketestablished ceramic ATZ (alumnia-toughened zirconia). In this study, it is used as a reference.

\section{Results and discussion}

\subsection{Material removal}

The presented quick-stop device allows the investigation of the occurring material removal phenomena in the contact zone between the grinding tool and the workpiece. The knowledge of these plasto-mechanical processes allows to examine the influence of the material removal on the subsurface workpiece properties. Figure 3 shows a SEM image of the contact zone and the different material removal phenomena, which may be present (Fig. 3a-e).

The spectrum of observed material removal phenomena covers phenomena from ductile material removal up to intercrystalline outbreaks including microgrooving and microploughing. The appearance of those material removal phenomena depends on the actual depth of cut of the grain

Table 3 Composition of the ceramics

\begin{tabular}{lllll}
\hline Oxide & & Empirical formula & SHYTZ & ATZ \\
\hline Zirconia & $(\%)$ & $\mathrm{ZrO}_{2}$ & 90.6 & 74.2 \\
Alumina & $(\%)$ & $\mathrm{Al}_{2} \mathrm{O}_{3}$ & 3.7 & 20.0 \\
Yttria & $(\%)$ & $\mathrm{Y}_{2} \mathrm{O}_{3}$ & 3.3 & 4.2 \\
Hafnia & $(\%)$ & $\mathrm{HfO}_{2}$ & 1.8 & 1.6 \\
Strontia & $(\%)$ & $\mathrm{SrO}$ & 0.6 & - \\
\hline
\end{tabular}

Table 4 Mechanical and thermal properties of the ceramics

\begin{tabular}{llll}
\hline & & SHYTZ & ATZ \\
\hline Bending strength $\sigma_{\mathrm{f}}$ & $(\mathrm{MPa})$ & $1528 \pm 175$ & $1447 \pm 125$ \\
Weibull module $m$ & & 10.3 & 13.2 \\
Fracture toughness $K_{\mathrm{Ic}}$ & $(\mathrm{MPa} \sqrt{\mathrm{m}})$ & 8.8 & 5.5 \\
Hardness HV1 & $(\mathrm{GPa})$ & 12.6 & 14.5 \\
Young's modulus $E$ & $(\mathrm{GPa})$ & 213 & 250 \\
Thermal conductivity $\lambda_{\left(300^{\circ} \mathrm{C}\right)}$ & $(\mathrm{W} / \mathrm{m} \mathrm{K})$ & 3.0 & 4.7 \\
Thermal diffusivity $a_{\left(300^{\circ} \mathrm{C}\right)}$ & $(\mathrm{mm} / \mathrm{s})$ & 0.9 & 1.3 \\
Specific heat capacity $c_{\mathrm{p}\left(300^{\circ} \mathrm{C}\right)}$ & $(\mathrm{J} / \mathrm{g} \mathrm{K})$ & 0.56 & 0.66 \\
\hline
\end{tabular}

that removes the material. The lowest risk of crack initiation occurs during ductile material removal due to the plastically deformed and smooth grinding groove ground. A higher penetration depth of the active grain leads to the phenomenon of microgrooving (Fig. 3b, c). Hereby, a triaxial hydrostatic compressive stress state occurs, which eventually leads to a plastic deformation of the material. Behind the active grain, the pressure on the material is then relieved. Consequently, chipping occurs behind the active grain if a critical surface pressure is exceeded (Fig. 3c). In this process, lateral and median cracks may result and decrease the strength of the material. In the case of microploughing, the material is plastically displaced to the sides by the active grain (Fig. 3d). This leads to crack initiation in the undeformed areas next to the grinding groove due to high plastic deformations. This causes inter-crystalline outbreaks with a size of about 0.27 and $0.33 \mu \mathrm{m}$ (Fig. 3e).

In Fig. 4, the proportion of the material removal phenomena is shown for both ceramics. For this purpose, a distinction is made between a ductile and a brittle material removal as well as a transition zone between them. This transition zone contains attributes of both material removal types. Therefore, every area of the contact zone, which shows signs of the phenomena of microgrooving or microploughing, is counted as a transition zone. Areas with inter-crystalline outbreaks are counted as brittle outbreaks. Furthermore, the influence of different grinding wheel specifications is investigated.

The ceramic SHYTZ shows a 3-5\% higher proportion of ductile removal mechanism than ATZ depending on the used grinding tool. The same applies to brittle outbreaks, whose proportion is between 2 and 3\% lower for SHYTZ than for ATZ. The reason for this is the higher hardness of ATZ combined with its lower fracture toughness compared with SHYTZ. ATZ shows an increased tendency to crack which leads to an increased proportion of brittle material removal. The reason for this is the increased tendency of ceramics to crack with increasing hardness and decreasing fracture toughness [14]. It should also be noted that the usage of a sintered metal bond leads to a 3-4\% higher proportion of brittle outbreaks, while at the same time the proportion of ductile 
Fig. 3 a-e Material removal phenomena in the contact zone

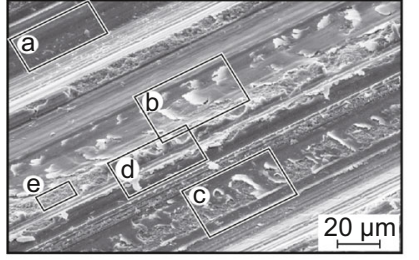

Microgrooving

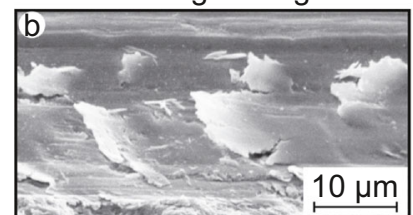

Microploughing

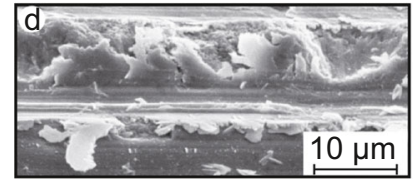

Process parameters:

Cutting speed: $v_{\mathrm{C}}=30 \mathrm{~m} / \mathrm{s}$

Feed velocity: $v_{\mathrm{ft}}=3,100 \mathrm{~mm}$

Depth of cut: $a_{e}=0.1 \mathrm{~mm}$

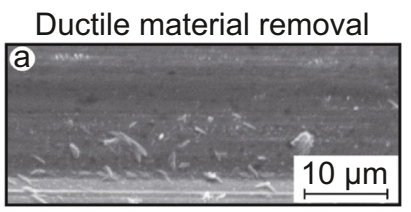

Microgrooving with chipping

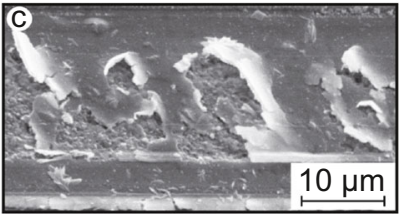

Inter-crystalline outbreaks

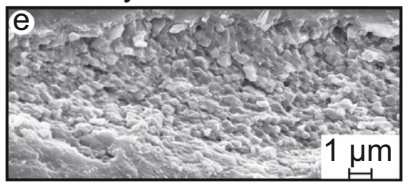

Grinding tool:

Abrasive:

D91

galvanic

Grain concentration:C189

material removal is reduced by $5-9 \%$. This indicates an increased tendency for crack initiation in case of the utilization of sintered metal bonds compared with resin-bonded tools.

\subsection{Single grain chip thickness}

For a deeper understanding of the thermal loads and the occurring material removal phenomena in the grinding process, it is necessary to determine the number of active grains and the single grain chip thickness. Due to the friction during material separation, each active grain is a heat source in the grinding process and thus influences the thermal load of the workpiece. In addition, the number of active grains influences the single grain chip thickness. The single grain chip thickness in turn influences the material removal phenomena that occur. Brittle

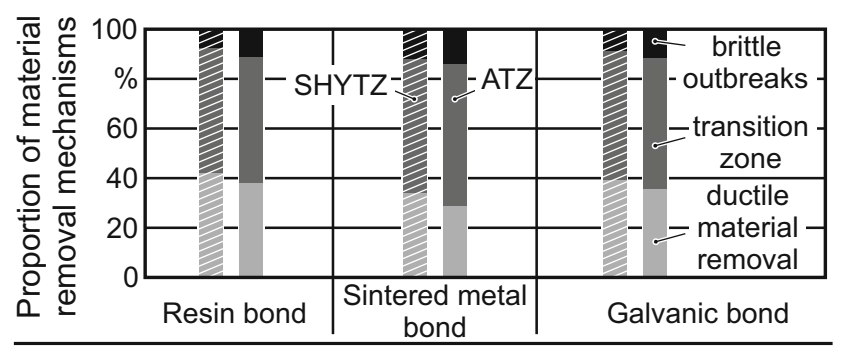

Process parameters:

Cutting speed: $\mathrm{v}_{\mathrm{C}}=30 \mathrm{~m} / \mathrm{s}$

Feed velocity: $v_{\mathrm{ft}}=3100 \mathrm{~m}$

Depth of cut: $a_{e}=0.1 \mathrm{~mm}$
Grinding tool:

Abrasive: D91

in Grain concentration: C150/ (resin/metal/galv.) C176/C189
Fig. 4 Proportion of material removal mechanisms material removal occurs when the single grain chip thickness is higher than the material-specific critical single grain chip thickness [23]. To determine the number of active abrasive grains $N_{\text {GaktA }}$ in the contact zone, all indications of active abrasive grains in the SEM images of the contact zone after the interruption of cut are counted. The identification criterion for an active grain is a change of the homogenous grinding grooves in the contact zone. Depending on the grain protrusion of the abrasive grains, the active grains leave different marks in the contact zone. Further identification marks for active grains are material accumulations, scratches, and grooves, which begin or end in the contact zone. Examples can be seen in Fig. 5 .

With this analysis, it is possible to determine the number of active grains experimentally instead of using analytical methods. In Fig. 6, the results of this analysis are shown for both ceramics and all bond types. To evaluate the number of active grains per square millimeter, the number of counted active grains is divided by the area of the contact zone. The number of active grains is between 8 and 17 active grains/ $\mathrm{mm}^{2}$. A comparison of the experimentally determined number of active grains with an analytical model is shown in Fig. 6. The material-independent model of Lierse is used for the analytical determination of the number of active grains [11]. It can be seen that there is a difference between the experimentally and the analytically determined number of active grains for all tools. In every case, the experimentally determined number of active grains is higher than the analytically determined number. The experimentally determined number of 
active grains is compared with the analytical model up to 14times higher if low feed velocities are used. Besides this, the number of active grains is negligibly higher for SHYTZ than for ATZ. The reason for this is the lower hardness of SHYTZ combined with its higher fracture toughness.

However, the bond of the grinding tool has a greater influence on the number of active grains. The high mechanical compliance of the resin bond leads to a high number of active grains at low feed velocities. The mechanical structure of the bond allows grains with lower grain protrusion to participate in the grinding process since the bond is deformed due to grinding forces [18]. At higher feed velocities, higher process forces are to be expected (see Fig. 10). In combination with the flexibility of the bond, this leads to a higher number of active grains, as the deformation of the bond allows grains deeper in the bond to participate in the grinding process. Overall, the number of active grains of the resin bonds is between 14 and 17 active grains $/ \mathrm{mm}^{2}$. The lower mechanical compliance of the sintered metal bond leads to a lower number of active grains. The lower grain protrusion of the sintered metal bond also contributes to this. The number of active grains of the sintered metal bond is therefore with 10 to 14 active grains $/ \mathrm{mm}^{2}$, the lowest compared with the other bonds. The galvanic bond shows 8 active grains $/ \mathrm{mm}^{2}$ for low feed velocities. However, the high grain concentration of this bond leads to an increase in the number of active grains to 16 active grains $/ \mathrm{mm}^{2}$ for higher feed velocities.

The differences between the experimentally and analytically determined numbers of active grains are caused by the assumptions of the analytical model. Lierse assumes that the material is neither elastically nor plastically deformed when the abrasive grain penetrates the workpiece and that the abrasive grain exactly separates the overlapping material volume.
Furthermore, the possibility of brittle outbreaks and their relevance for the number of active grains is neglected. The mechanical compliance of the bond is also neglected. The only tool-related parameter that is taken into account in this model is the abrasive grain density $N_{\mathrm{GV}}$ which is also used in Lierse's calculation of the single grain chip thickness $h_{\mathrm{cu}}$ [11]. The method of analysis used in the present paper makes it possible to determine the number of active grains without using simplifying assumptions.

Considering that the number of active grains also influences the single grain chip thickness, Fig. 7 shows a comparison of the single grain chip thickness for all bonds. The single grain chip thickness is calculated with the experimentally determined number of active grains using the analytical model of Lierse [11]. It can be seen that the different numbers of active grains in the bonds lead to different single grain chip thicknesses for each bond. Therefore, the single grain chip thickness of the resin bond is up to $12.1 \%$ lower than for the galvanic bond and up to $7.9 \%$ lower than for the sintered metal bond. It can also be seen that the single grain chip thickness based on the experimentally determined number of active grains is smaller than in the analytical model. This is not negligible as it has an influence on the material removal phenomena [23].

\subsection{Mechanical and thermal loads}

With the previously obtained knowledge about the number of active grains, it is possible to determine the mechanical and thermal loads on a single grain. For the mechanical loads, this is shown exemplarily in Fig. 8 with regard to the influence of the cutting speed. The grain normal and tangential forces $\left(F_{\mathrm{nG}}\right.$, $\left.F_{\mathrm{tG}}\right)$ can be calculated by dividing the normal and tangential

Fig. 5 SEM image of the contact zone for analysis of active abrasive grains

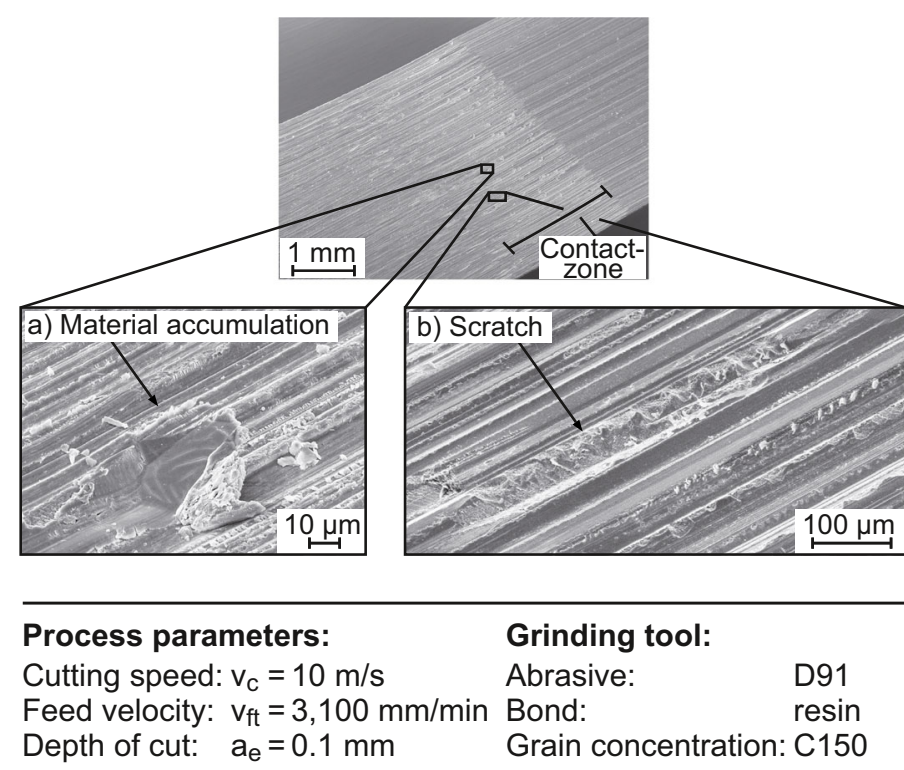


Fig. 6 Number of active grains in the contact zone

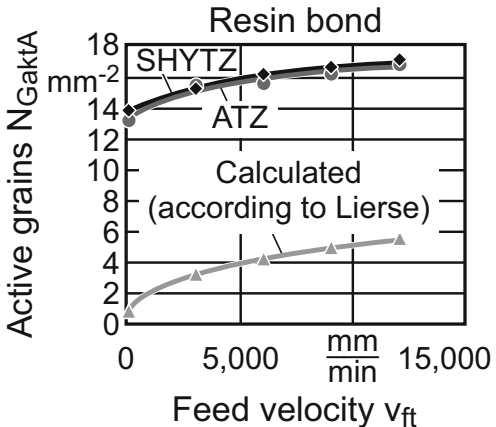

Sintered metal bond

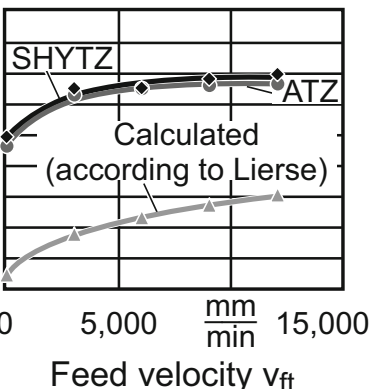

Galvanic bond

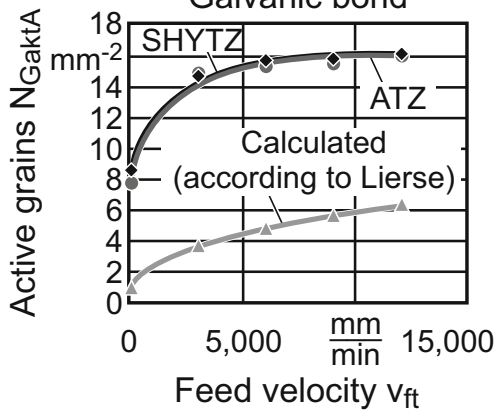

Process parameters:

Cutting speed: $v_{\mathrm{c}}=30 \mathrm{~m} / \mathrm{s}$

Feed velocity: $v_{\mathrm{ft}}=$ var.

Depth of cut: $a_{e}=0.1 \mathrm{~mm}$

Grinding tool:

Abrasive: D91

Grain con-

centration: C150 (resin)

C176 (metal)

C189 (galv.) forces by the number of active grains. This allows a more reliable assessment of the mechanical loads in the contact zone between grain and material compared with the specific normal and tangential force. Any possible friction between the bond and the workpiece can be neglected in this case due to a high grain protrusion of the tools combined with the comparable low single grain chip thickness [54].

An increase in the cutting speed with a constant material removal rate leads to a degressive load drop due to a lower single grain chip thickness, as it can be seen in Fig. 8. It also shows that the process forces for machining ATZ are higher than for SHYTZ, regardless of the cutting speed. Higher mechanical loads in the grinding process increase the risk of crack formation. It should be noted that cracks have the potential to negatively influence the flexural strength of the ceramics. It is possible to reduce the mechanical load by increasing the cutting speed, but at the same time this leads to an increase in the thermal load.

Investigations of the influence of the feed velocity and the depth of cut show that in general the process forces for the machining of ATZ are higher than for SHYTZ, as shown in Figs. 9 and 10. Regarding the grain forces, this means that the grain normal forces are $18-31 \%$ higher for the machining of ATZ. The same applies to the grain tangential forces which are 25-28\% higher for ATZ than for SHYTZ.

The reason for this is the higher hardness of ATZ in comparison with SHYTZ. These results show that the mechanical load in grinding of ATZ is higher than for grinding of SHYTZ. It must therefore be assumed that ATZ has a higher risk of crack initiation as a result of the grinding process due to the higher mechanical load. The analysis of the experimental results of all bonds shows that the grain forces of the sintered metal bond are higher than for the other bonds. The reason for this is the comparatively low number of active grains and a lower grain protrusion of the sintered metal bond [51].

The strength of the ceramics can be influenced not only by mechanical but also by thermal loads. To determine the thermal loads in the grain contact zone, it is necessary to determine the heat distribution factor $R_{\mathrm{W}} \cdot R_{\mathrm{W}}$ describes the percentage of the specific cutting power that passes into the workpiece as heat flow $q_{\mathrm{w}}$. The heat distribution factor can be calculated using the following equation:

$R_{W}=\frac{q_{w} \cdot l_{g}}{F^{\prime}{ }_{t} \cdot v_{c}}$

This factor can then be used to calculate the temperatures in the grain contact zone using an analytical model [55-57]. Before the calculation of the temperatures in the grain contact can be carried out, it is necessary to verify that the temperatures are calculated correctly. To verify the calculated temperatures in the contact zone, they are compared with the measured temperatures in the contact zone as shown by various authors [54, 58-61]. Figure 11 shows the comparison of measured and calculated temperature. It can be seen that when using heat distribution factors of 9 and $10 \%$, the calculated values almost correspond to the measured values with a maximum deviation of $2.3 \%$.

The heat distribution factor is influenced by the process parameters and the machined material [60]. Therefore, Fig. 12 shows the grinding temperature $T_{\max }$ and the heat distribution factor as a function of the cutting speed. It can be seen that 
Fig. 7 Comparison of single grain chip thicknesses
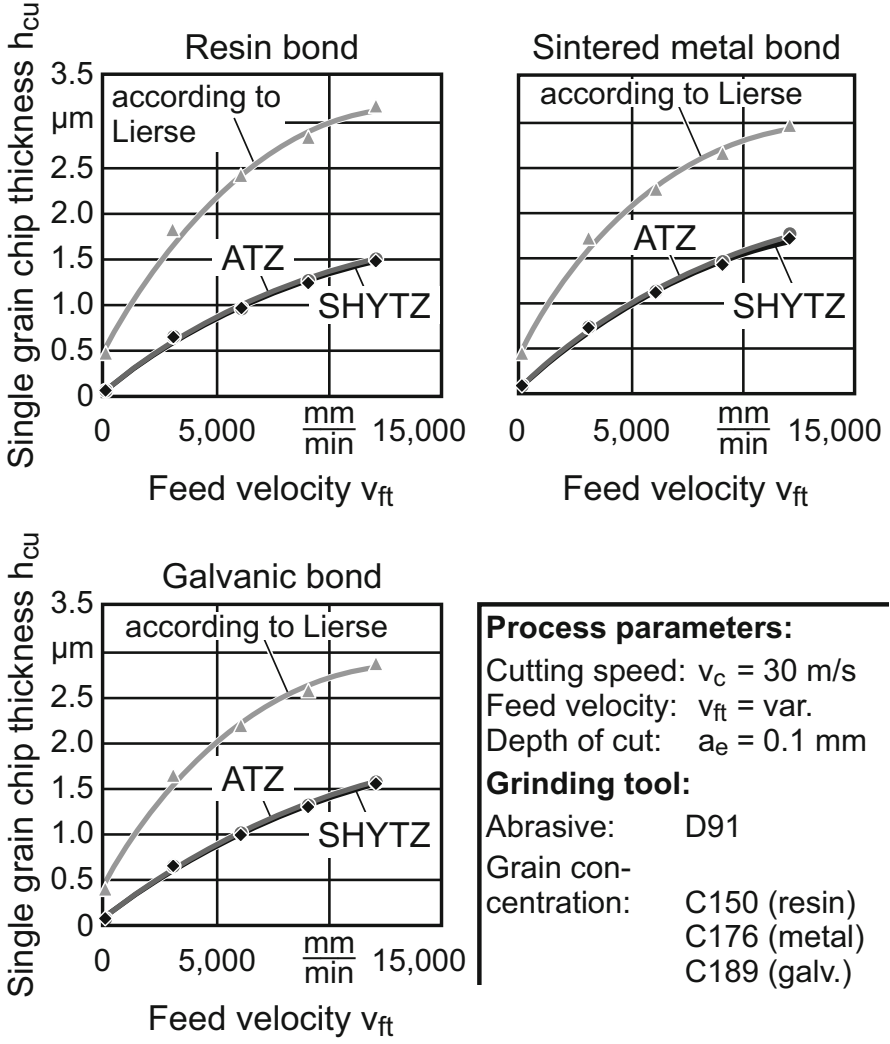

both the grinding temperature and the heat distribution factor increase with increasing cutting speed. The reason for this is mainly the simultaneous increase of the specific cutting power and the higher number of grain engagements per time when the cutting speed is increased. The steeper increase of the temperature and heat distribution factor for ATZ results from its higher thermal conductivity and thermal diffusivity. The calculated temperatures represent the mean grinding temperature resulting from the superposition of the single grain interventions and the resulting local grain contact temperatures of the active grains.

Due to the fact that high thermal loads can cause phase transformations in the ceramics or locally alter stress states, it is more meaningful to analyze the grain contact temperature than the mean grinding temperature. Therefore, an analytical model [55-57] is applied to calculate the grain contact temperature with Eqs. (8)-(14). Hereby, $T(\mathrm{x}, \mathrm{z})$ is the temperature at a specific place, $q_{\mathrm{wG}}$ the heat flow from a single grain, $K_{0}$ the modified Bessel function of the second kind and zeroth order, $l_{\mathrm{gG}}$ the grain contact length, $R_{\mathrm{G}}$ the grain radius, and $X$, $Z, L$, and $u$ are dimensionless parameters.

$$
\begin{aligned}
& T(x, z)=\frac{2 \cdot q_{w G} \cdot a}{\pi \cdot \lambda \cdot v_{c}} \cdot \int_{X-L}^{X+L} e^{-u} \cdot K_{0} \cdot\left(Z^{2}+u^{2}\right)^{\frac{1}{2}} \cdot d_{u} \\
& q_{w G}=R_{W} \cdot \frac{F_{t G} \cdot v_{c}}{l_{g G}}
\end{aligned}
$$
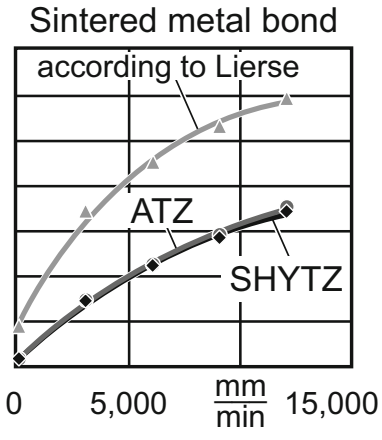

\begin{tabular}{|c|c|}
\hline \\
\hline \multicolumn{2}{|c|}{$\begin{array}{l}\text { Process parameters: } \\
\text { Cutting speed: } v_{c}=30 \mathrm{~m} / \mathrm{s} \\
\text { Feed velocity: } v_{\mathrm{ft}}=\mathrm{var} . \\
\text { Depth of cut: } a_{\mathrm{e}}=0.1 \mathrm{~mm}\end{array}$} \\
\hline \multicolumn{2}{|c|}{ Grinding tool: } \\
\hline Abrasive: & D91 \\
\hline $\begin{array}{l}\text { Grain con- } \\
\text { centration: }\end{array}$ & $\begin{array}{l}\text { C150 (resin) } \\
\text { C176 (metal) } \\
\text { C189 (galv.) }\end{array}$ \\
\hline
\end{tabular}

Feed velocity $v_{\mathrm{ft}}$

$l_{g G}=R_{G} \cdot \arccos \left(1-\frac{h_{c u}}{R_{G}}\right)$

$X=\frac{v_{f t} \cdot x}{2 \cdot a}$

$Z=\frac{v_{f t} \cdot z}{2 \cdot a}$

$L=\frac{v_{f t} \cdot l_{g}}{4 \cdot a}$

$u=\frac{v_{f t} \cdot\left(x-x_{0}\right)}{2 \cdot a}$

The abrasive grain is considered as a heat source that moves with the cutting speed. In Fig. 13, the calculated grain contact temperatures are shown as a function of cutting speed and depth of cut.

The presented increase of the grain contact temperature due to higher cutting speeds results from the corresponding decrease of the single grain chip thickness. With a reduction of the single grain chip thickness, each active grain has to remove less material, resulting in a higher relative share of friction. This eventually leads to higher temperatures. It can be seen that higher cutting speeds lead to a higher difference in the grain contact temperature of ATZ and SHYTZ. A steeper increase of the temperature can be observed for ATZ analogous to the previous mentioned grinding temperature in the contact zone. The higher cutting speed leads to an increase of 

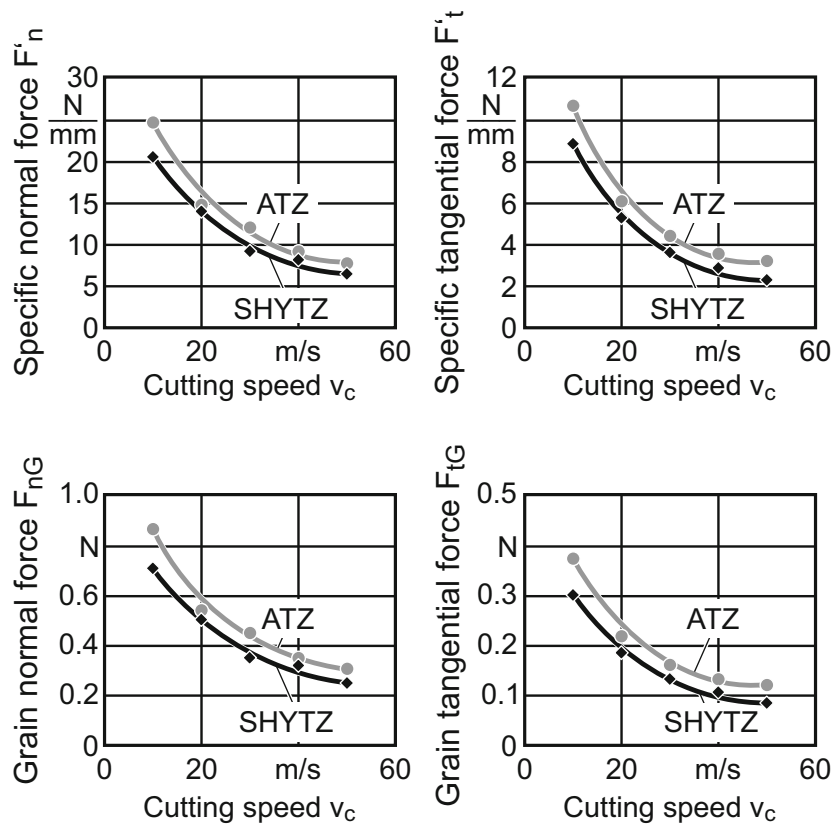

Process parameters:

Grinding tool:

Abrasive:

D91

Cutting speed: $\mathrm{v}_{\mathrm{C}}=$ var.

Bond:

resin

Feed velocity: $v_{\mathrm{ft}}=3,100 \mathrm{~mm}$
Depth of cut: $a_{\mathrm{e}}=0.1 \mathrm{~mm}$

Grain concentration: C150

Fig. 8 Process forces of the grinding process

the grain contact temperature for ATZ of up to $52 \%$ compared with SHYTZ. For increasing depths of cut, the grain contact temperatures of both ceramics are comparable with a maximal difference of $5 \%$ for a depth of cut of $0.18 \mathrm{~mm}$. The higher grain contact temperatures for higher depth of cuts result from the greater contact length which leads to a longer friction distance. This increases the energy demand for the material deformation.

A variation of the feed velocity has a minor influence on the grain contact temperature compared with the cutting speed and the depth of cut as shown in Fig. 14. The displayed experimental results show that the grain contact temperature is at its highest when a grinding tool with a sintered metal bond is

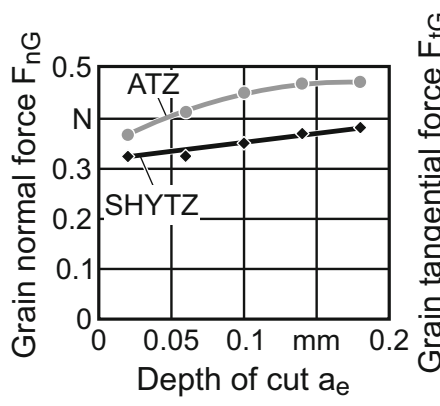

Process parameters:

Cutting speed: $\mathrm{v}_{\mathrm{C}}=30 \mathrm{~m} / \mathrm{s}$

Feed velocity: $v_{\mathrm{ft}}=3,100 \mathrm{~mm} / \mathrm{min}$

Depth of cut: $a_{e}=$ var.

Fig. 9 Grain forces as function of depth of cut

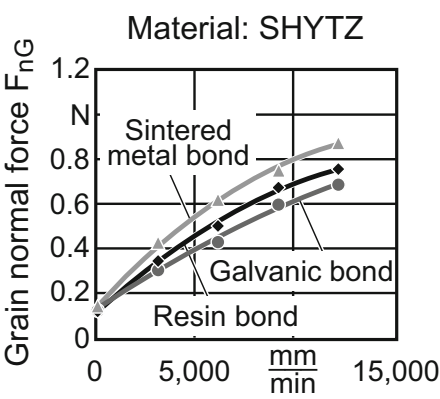

Feed velocity $v_{\mathrm{ft}}$

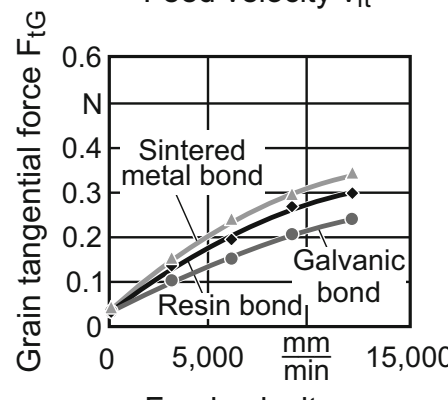

Feed velocity $v_{\mathrm{ft}}$

\section{Process parameters:}

Cutting speed: $\mathrm{v}_{\mathrm{c}}=30 \mathrm{~m} / \mathrm{s}$

Feed velocity: $v_{\mathrm{ft}}=$ var.

Depth of cut: $a_{e}=0.1 \mathrm{~mm}$
Material: ATZ
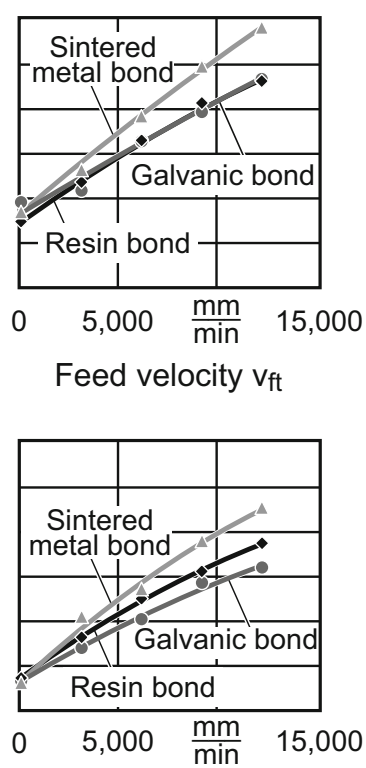

Feed velocity $v_{\mathrm{ft}}$
Fig. 10 Grain forces as function of feed velocity

used and at its lowest when a tool with a galvanic bond is used. It can also be seen that the grain contact temperature has a minimum around feed rates of $3000 \mathrm{~mm} / \mathrm{min}$ before the grain temperature rises again. The influence of feed velocity can be attributed to the opposite relationship between heat input and heat dissipation with increasing feed velocity. On the one hand, higher feed velocities increase the temperature, as the power used to deform the material increases. On the other hand, thermally stressed material areas are removed more quickly, which limits heat propagation into the material [9]. However, this is negligible in this case, as the constant cutting speed for all feed velocities determines the relative

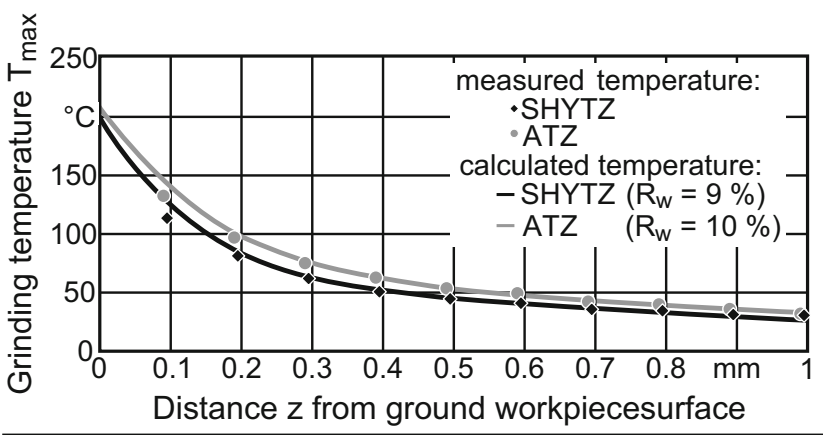

\section{Process parameters: \\ Grinding tool: \\ Cutting speed: $v_{\mathrm{c}}=30 \mathrm{~m} / \mathrm{s}$ Abrasive: \\ D91 \\ Feed velocity: $v_{\mathrm{ft}}=3,100 \mathrm{~mm} / \mathrm{min}$ Bond: resin}

Depth of cut: $a_{e}=0.1 \mathrm{~mm}$

Grain concentration: C150

Fig. 11 Comparison of measured and calculated temperature 

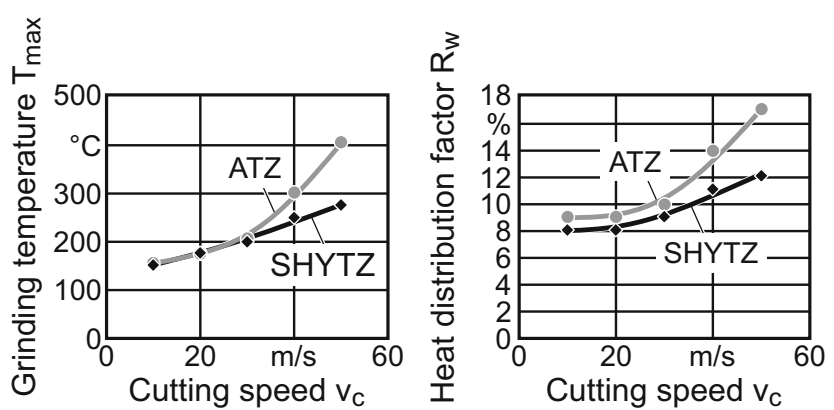

\begin{tabular}{lll}
\hline Process parameters: & Grinding tool: & \\
Cutting speed: $\mathrm{v}_{\mathrm{c}}=\mathrm{var}$. & Abrasive: & $\mathrm{D} 91$ \\
Feed velocity: $\mathrm{v}_{\mathrm{ft}}=3,100 \mathrm{~mm} / \mathrm{min}$ & Bond: & resin \\
Depth of cut: $\mathrm{a}_{\mathrm{e}}=0.1 \mathrm{~mm}$ & Grain concentration: $\mathrm{C} 150$
\end{tabular}

Fig. 12 Grinding temperature and heat distribution factor as function of cutting speed

movement between the abrasive grains as heat source and the workpiece as heat sink. Furthermore, the heat distribution factor increases with increasing cutting speed [11], which also increases the amount of heat transferred to the workpiece. The number of active grains has also an influence on the grain temperature. Higher feed velocities lead to a higher number of active grains which can transfer heat out of the contact zone into the tool bond. However, the number of active grains increases slower with higher feed velocities (see Fig. 6) while the power required for material deformation rises steadily. This ultimately leads to an increase of the grain contact temperature for higher feed velocities.

The reason for the higher grain contact temperatures of the sintered metallic bond is the low number of active grains of this bond. With a low number of active grains, a smaller amount of heat can be conducted by the grains into the bond. This leads to grain contact temperatures that are up to $46 \%$ higher than for the galvanic bond and therefore to a higher thermal load in the contact zone. Overall, it can be stated that
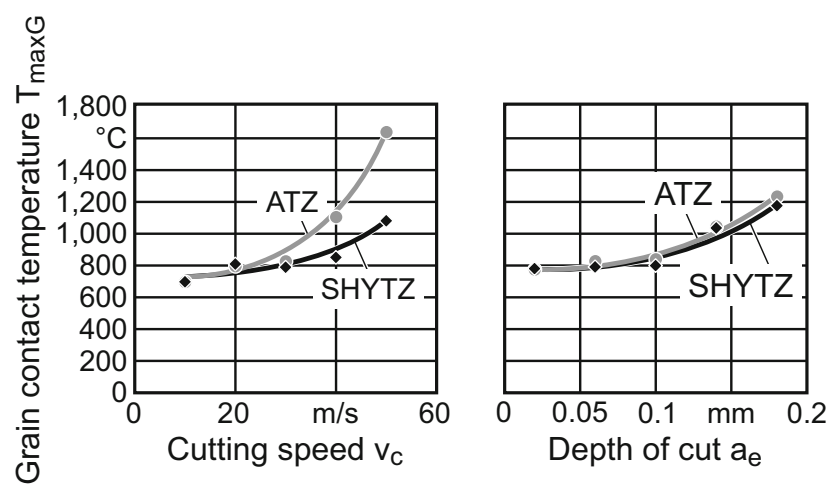
Process parameters:
Cutting speed: $\mathrm{v}_{\mathrm{C}}=$ var.
Grinding tool:
Abrasive:
D91
Feed velocity: $v_{\mathrm{ft}}=3,100 \mathrm{~mm} / \mathrm{min}$ Bond:
resin
Depth of cut: $a_{e}=$ var.
Grain concentration: C150

Fig. 13 Calculated grain contact temperatures the grain contact temperatures during grinding are higher for ATZ than for SHYTZ. For both ceramics, the calculated grain contact temperature reaches values above $1000^{\circ} \mathrm{C}$, which can lead to a strength-influencing retransformation from the monoclinic into the tetragonal crystal structure of the zirconia.

\subsection{Residual stresses and bending strength}

The grinding process can cause microcracks and phase transformations in the ceramics which influence the stress state in the subsurface area of the material. This is often associated with a decrease of its bending strength. In Fig. 15, this is displayed for a variation of the feed velocity and the grinding tool composition. Compared with the initial state (see Table 4) of the ceramics, the bending strength of both materials is reduced for every factor due to grinding-induced damages. For the tools with a resin bond and a galvanic bond, a similar course of the bending strength can be observed. The maximum value for the bending strength lies between a feed velocity of 3000 and $6000 \mathrm{~mm} / \mathrm{min}$.

In contrast to this, the tool with a sintered metal bond already reaches the maximum bending strength at a feed velocity of $3000 \mathrm{~mm} / \mathrm{min}$. Afterwards, the bending strength is significantly reduced. It even decreases for the sintered metal bond and in one case for the resin bond below the limit value of the bending strength for implants of $800 \mathrm{MPa}$ specified in DIN EN ISO 13356. This is due to the combination of the highest grain contact temperatures and the highest grain forces of the sintered metal bond in comparison with the other tools. For SHYTZ, this means a reduction of the bending strength of up to $42 \%$ to $632 \mathrm{MPa}$ and for ATZ a reduction of up to $61 \%$ to $432 \mathrm{MPa}$. The generally lower bending strength for lower feed velocities indicates a negative influence of thermal loads which are higher for lower feed velocities. Another reason for
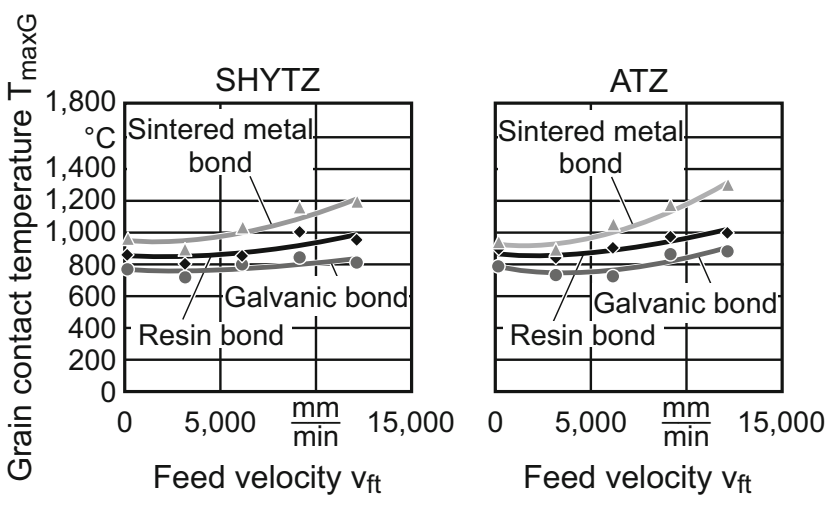

\begin{tabular}{|c|c|}
\hline Process parameters: & Grinding tool: \\
\hline Cutting speed: $\mathrm{v}_{\mathrm{c}}=30 \mathrm{~m} / \mathrm{s}$ & Abrasive: \\
\hline eed velocity: $\mathrm{v}_{\mathrm{ft}}=$ var. & Grain concentration: C150/ \\
\hline epth of cut: $a_{e}=$ & (resin/metal/galv.) \\
\hline
\end{tabular}

Fig. 14 Calculated grain temperature as function of feed velocity 
this is the lower number of active grains for lower feed velocities which can convey forces and heat.

However, cutting speed and depth of cut have a greater influence on the bending strength as can be seen in Fig. 16. For ATZ, a decrease of the bending strength of up to $69 \%$ with increasing cutting speed can be observed. This correlates with the high thermal load of the material. For SHYTZ, this reduction of the bending strength is only up to $29 \%$. Similar observations can be made for an increase of the depth of cut. This leads to a reduction of the bending strength of up to $70 \%$ for ATZ and up to $35 \%$ for SHYTZ.

The bending strength is not only influenced by surface defects and microcracks but also by residual stresses. Residual stresses can occur in the grinding process due to inhomogeneous plastic deformations of the material and thermal loads as a consequence of the engagement of the abrasive grains. Furthermore, for transformation-toughened mixed oxide ceramics, an increase of strength can occur as a result of the phase transformation of the zirconia. Tension-induced tetragonal to monoclinic phase transformations shift the residual stresses into the compressive stress range due to a volumetric growth of the zirconia grains in this process. High thermal loads inhibit the phase transformation and can cause a retransformation from the monoclinic to the tetragonal phase, thus shifting the residual stresses into a tensile stress range.

The experimental results show a correlation between the residual stresses, the measured bending strength, and the monoclinic phase content. Because of the high thermal load of the workpieces when using the tool with sintered metal bonding, only low residual compressive stresses are present in the material after grinding (see Fig. 17). The high thermal load when using the tool with sintered metal bonding is a result of its low number of active grains. The small number of active grains limits the heat dissipation via the abrasive grain into the bond. An increase of the feed velocity leads to the generation of tensile residual stresses. This explains in combination with the low monoclinic phase content the loss
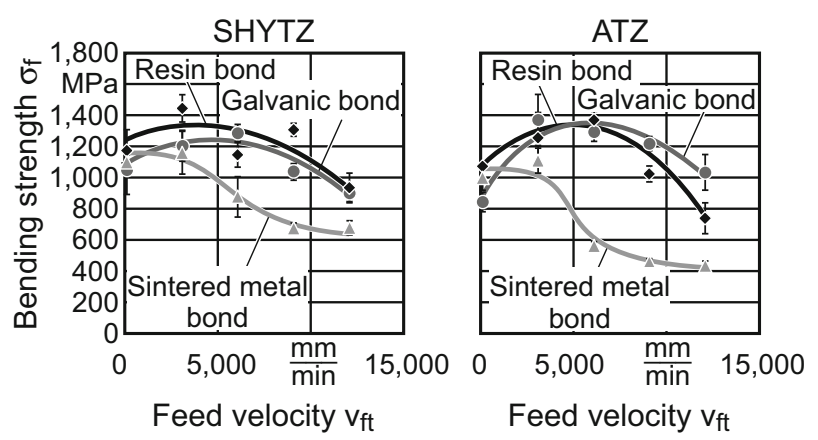

\section{Process parameters:}

Feed velocity: $v_{\mathrm{ft}}=$ var.

Depth of cut: $a_{e}=0.1 \mathrm{~mm}$
Cutting speed: $\mathrm{v}_{\mathrm{c}}=30 \mathrm{~m} / \mathrm{s}$

\section{Grinding tool: \\ Abrasive: D91 \\ Grain concentration: C150/ \\ (resin/metal/galv.) C176/C189}

Fig. 15 Bending strength as function of feed velocity of bending strength (see Fig. 15). The highest compressive residual stresses are reached for the usage of a tool with galvanic bonding due to the lower thermal loads in this case.

Analogous to the previous results, the residual stresses as a function of cutting speed and depth of cut also correlate with the bending strength and the monoclinic phase content (see Figs. 16 and 18). Due to the high thermal loads, the residual stresses are also shifted into the tensile stress range with an increase of cutting speed and/or depth of cut. The previously observed tendencies for the influence of the grinding process on SHYTZ and ATZ can also be observed in this case. The residual compressive stresses and monoclinic phase contents are in every case lower for ATZ than for SHYTZ. This is caused by the higher stabilizer content in ATZ, which makes higher grindinginduced loads necessary to trigger a phase transformation of the zirconia to the monoclinic phase.

\section{Conclusion}

This paper investigates the occurring material removal phenomena, the number of active grains, and the thermomechanical loads and their influence on bending strength and residual stresses during grinding of two mixed oxide ceramics by using an innovative quick-stop device. Based on the obtained results, the following conclusions can be drawn:

- The newly developed ceramic SHYTZ shows a lower amount of brittle material removal and a higher amount of ductile material removal than the market-established ceramic ATZ.

- With the presented method, it is possible to determine the number of active grains and the single grain chip thickness experimentally instead of analytically.

- The experimentally determined number of active grains was found to be higher than the analytically determined
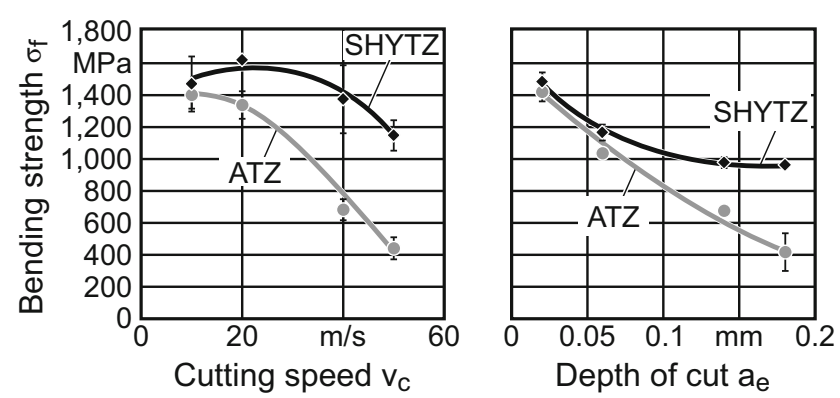

\begin{tabular}{lll}
\hline Process parameters: & Grinding tool: & \\
Cutting speed: $v_{\mathrm{c}}=$ var. & Abrasive: & $\mathrm{D} 91$ \\
Feed velocity: $v_{\mathrm{ft}}=3,100 \mathrm{~mm} / \mathrm{min}$ & Bond: & resin \\
Depth of cut: $a_{\mathrm{e}}=$ var. & Grain concentration: $\mathrm{C} 150$
\end{tabular}

Fig. 16 Bending strength as a function of cutting speed and depth of cut 
Fig. 17 Residual stresses and monoclinic phase content as function of feed velocity a) Material: SHYTZ

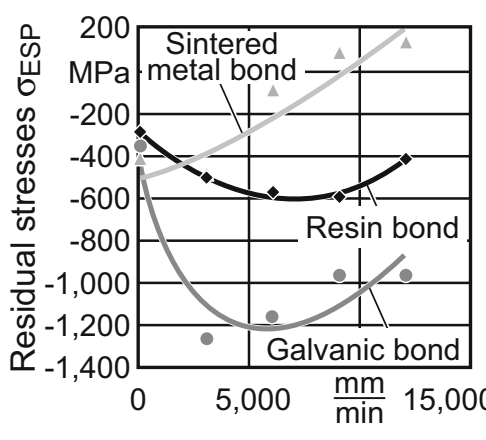

Feed velocity $\mathrm{v}_{\mathrm{ft}}$

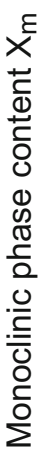

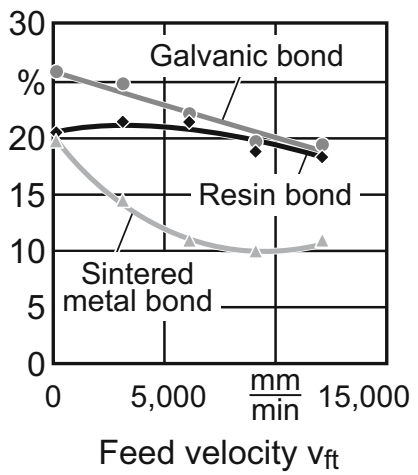

b) Material: ATZ
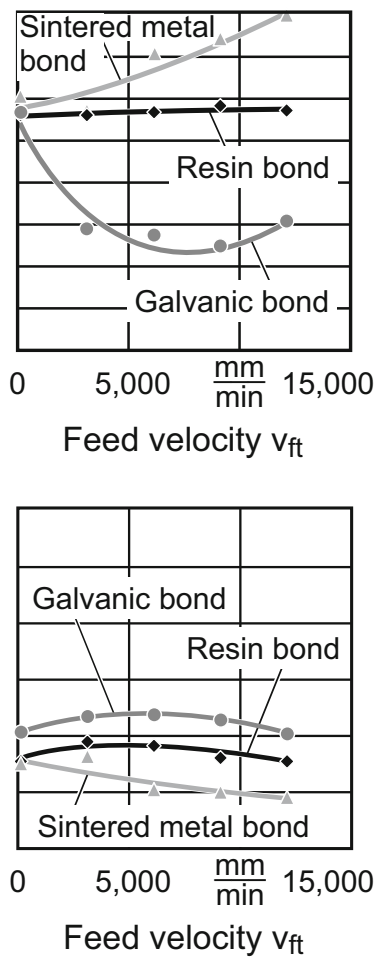

Process parameters:

Cutting speed: $\mathrm{v}_{\mathrm{C}}=30 \mathrm{~m} / \mathrm{s}$

Feed velocity: $v_{\mathrm{ft}}=$ var.

Depth of cut: $a_{e}=0.1 \mathrm{~mm}$

\section{Grinding tool:}

Abrasive:

Grain concentration:

(resin/metal/galv.) C176/C189 number of active grains. This influences the determination of single grain chip thickness and the design of the grinding process.

- The thermal and mechanical loads during grinding of ATZ are higher than for SHYTZ due to the higher hardness and lower thermal conductivity of ATZ.

- The lower thermomechanical loads in grinding of SHYTZ and the subsequently higher monoclinic phase content lead to a higher bending strength and compressive residual stresses for SHYTZ than for ATZ.

- $\quad$ SHYTZ can be manufactured with higher process loads than ATZ while influencing its bending strength to the same extent.

- The grinding tool bond influences the number of active grains, the thermomechanical loads, and thus also the bending strength and residual stresses of the ground ceramics. The results show that higher compressive residual stresses and bending strengths can be achieved with resin or galvanic bonded tools. The use of a sintered metalbonded tool leads in comparison to a decrease of these properties.
Acknowledgments The authors would like to thank the German Research Foundation (DFG) for supporting the subproject T5 within the Collaborative Research Center 599 "Sustainable bioresorbable and permanent implants of metallic and ceramic materials".

Funding information Open Access funding provided by Projekt DEAL. This research project was funded by the German Research Foundation (DFG) within the subproject T5 of the Collaborative Research Center 599 "Sustainable bioresorbable and permanent implants of metallic and ceramic materials".

\section{Compliance with ethical standards}

Conflict of interest The authors declare that they have no conflict of interest.

Open Access This article is licensed under a Creative Commons Attribution 4.0 International License, which permits use, sharing, adaptation, distribution and reproduction in any medium or format, as long as you give appropriate credit to the original author(s) and the source, provide a link to the Creative Commons licence, and indicate if changes were made. The images or other third party material in this article are included in the article's Creative Commons licence, unless indicated otherwise in a credit line to the material. If material is not included in the article's Creative Commons licence and your intended use is not permitted by statutory regulation or exceeds the permitted use, you will need to obtain 
Fig. 18 Residual stresses and monoclinic phase content as function of cutting speed and depth of cut
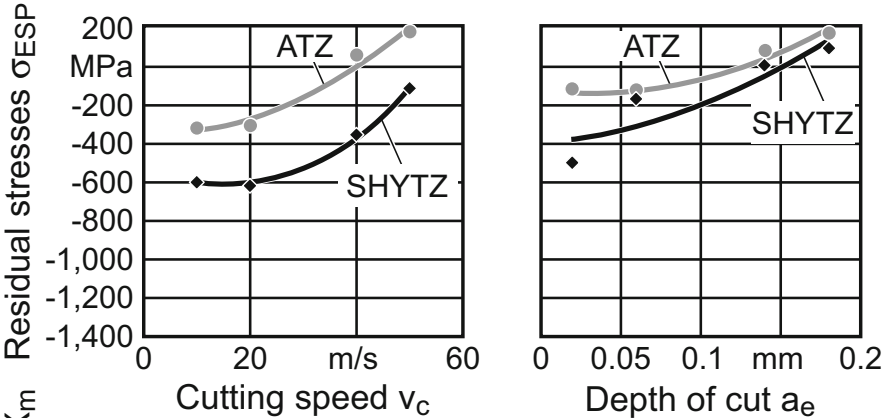

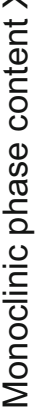
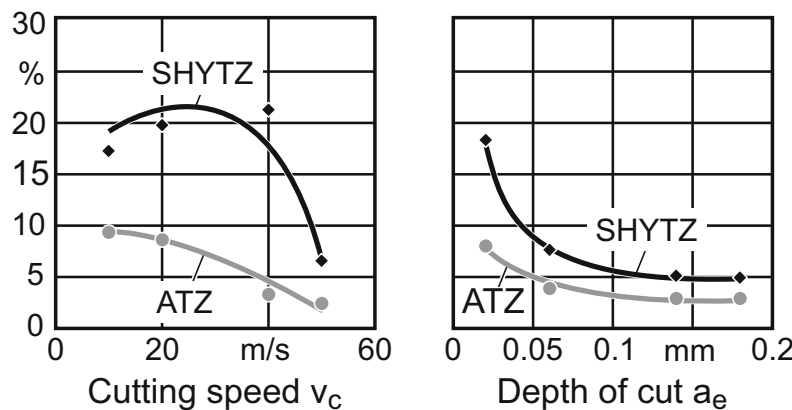

Process parameters:

Grinding tool:

Abrasive:

D91

Feed velocity: $v_{\mathrm{ft}}=3,100 \mathrm{~mm} / \mathrm{min}$ Bond:

resin

Depth of cut: $a_{e}=$ var.

Grain concentration: C150 permission directly from the copyright holder. To view a copy of this licence, visit http://creativecommons.org/licenses/by/4.0/.

\section{References}

1. Chevalier J, Gremillard L (2011) Zirconia as a biomaterial. In: Paul D (ed) Comprehensive biomaterials. Elsevier, Oxford, pp 95-108

2. Ha SW, Wintermantel E (2009) Biokompatible Keramische Werkstoffe. In: Ha SW, Wintermantel E (eds) Medizintechnik. Springer, Berlin, Heidelberg, pp 277-297

3. Garvie RC, Hannink RH, Pascoe RT (1975) Ceramic steel. Nature 258(5537):703-704

4. Chevalier J, Gremillard L, Virkar AV, Clarke DR (2009) The tetragonal-monoclinic transformation in zirconia: lessons learned and future trends. J Am Ceram Soc 92(9):1901-1920

5. Seghezzi HD, Wasmer R (2009) Qualitätsmanagementsysteme Teil 1. In: Ha SW, Wintermantel E (eds) Medizintechnik. Springer, Berlin, Heidelberg, pp 2107-2125

6. Tönshoff, H.K.; Wobker,H. G.; Lierse, T.: Randzoneneigenschaften und Oberflächenausbildung geschliffener Aluminiumoxidkeramik. Mater Werkst 27(7): p. 323-330, 1996

7. Wobker HG (1992) Schleifen keramischer Schneidstoffe. Dissertation, Hannover, Universität Hannover, Dr.-Ing

8. Malkin S, Ritter JE (1992) Grinding mechanisms and strength degradation for ceramics. Key Eng Mater 71:195-212

9. Uhlmann EG (1993) Tiefschleifen hochfester keramischer Werkstoffe. Dissertation, Berlin, Technische Universität Berlin, Dr.-Ing
10. Hessert R (1998) Bearbeitungseigenspannungen, Randschichtenschädigungen und Festigkeiten geschliffener $\mathrm{Al}_{2} \mathrm{O}_{3}$ - und $\mathrm{ZrO}_{2}-$ Keramiken. Dissertation, Karlsruhe, Universität Karlsruhe, Dr.-Ing

11. Lierse T (1998) Mechanische und thermische Wirkungen beim Schleifen keramischer Werkstoffe. Dissertation, Hannover, Universität Hannover, Dr.-Ing

12. Zhang B, Zheng XL, Tokura H, Yoshikawa M (2003) Grinding induced damage in ceramics. J Mater Process Technol 132(1-3): 353-364

13. Luthardt RG, Holzhüter MS, Rudolph H, Herold V, Walter MH (2004) CAD/CAM-machining effects on Y-TZP zirconia. Dent Mater 20(7):655-662

14. Möhlen H (1995) Beitrag zum Schleifen hochfester keramischer Werkstoffe. Dissertation, Braunschweig, Technische Universität Braunschweig, Dr.-Ing

15. Klocke F, Hilleke M (1995) Sinhoff, V.: Hochleistungskeramik im Automobilbau: nur eine Vision? VDI-Z 137:20-23

16. Brinksmeier E (1991) Prozess- und Werkstückqualität in der Feinbearbeitung. Hannover, Universität Hannover, Habilitation thesis

17. Agarwal S, Rao PV (2008) Experimental investigation of surface/ subsurface damage formation and material removal mechanisms in SiC grinding. Int J Mach Tool Manu 48:698-710

18. Steffens K (1983) Thermomechanik des Schleifens. Dr.-Ing, Dissertation, Aachen, Rheinisch-Westfälische Technische Hochschule Aachen

19. Lawn BR, Wilshaw TR (1975) Indentation fracture: principles and applications. J Mater Sci 10(6):1049-1081

20. Lawn BR, Swain MV (1975) Microfracture beneath point indentation in brittle solids. J Mater Sci 10(1):113-122

21. Inasaki I (1987) Grinding of hard and brittle materials. CIRP AnnManuf Technol 36(2):463-471 
22. Malkin S, Hwang TW (1996) Grinding mechanisms for ceramics. CIRP Ann 45(2):569-580

23. Bifano TG (1988) Ductile-Regime Grinding of Brittle Materials. In: Ductile-regime grinding of brittle materials. North Carolina, North Carolina State University, $\mathrm{PhD}$-Thesis

24. Jahanmir, S.; Ives, L.K.; Ruff, A.W.; Peterson, M.B.: Ceramic machining: assessment of current practice and research needs in the United States. National Institute of Standards and Technology, Special Publication 834, U.S. Government Printing Office, Washington, 1992

25. Busch DM (1968) Ritz- und Verschleißuntersuchungen an spröden Werkstoffen mit einkornbestückten Hartstoffwerkzeugen. Dr.-Ing, Dissertation, Hannover, Technische Hochschule Hannover

26. Grof HE (1977) Beitrag zur Klärung des Trennvorganges beim Schleifen von Metallen. Dissertation, Munich, Technische Universität München, Dr.-Ing

27. Kitajima K, Cai GQ, Kurnagai N, Tanaka Y, Zheng HW (1992) Study on mechanism of ceramics grinding. CIRP Ann-Manuf Technol 41(1):367-371

28. Martin K, Yegenoglu K (1992) HSG - Technologie. Handbuch zur praktischen Anwendung, Guehring Automation GmbH, Frohnstetten

29. Ardelt, T.; Barth, C.; Daus, N.; Eichgrün, K.; Hessel, D.; Kreis, R.; Pähler, D.; Schäfer, L.; Schmidt, C; Sprengler, C.; Sroka, R.: Charakterisierung keramischer Oberflächen, Teil 1. IDR 35(2): p. 171-179, 2001

30. Ardelt, T.; Barth, C.; Daus, N.; Eichgrün, K.; Hessel, D.; Kreis, R.; Pähler, D.; Schäfer, L.; Schmidt, C; Sprengler, C.; Sroka, R.: Charakterisierung keramischer Oberflächen, Teil 2. IDR 35(4): p. 346-351, 2001

31. Barth C (2002) Dynamische Kontaktzonenvorgänge beim Schleifen sprödharter Werkstoffe. Dissertation, Kaiserslautern, Technische Universität Kaiserslautern, Dr.-Ing

32. Agarwal S, Rao PV (2012) Predictive modeling of undeformed chip thickness in ceramic grinding. Int J Mach Tool Manu 56:5968

33. Arai S, Wilson SA, Corbett J, Whatmore RW (2009) Ultraprecision grinding of PZT ceramics - surface integrity control and tooling design. Int J Mach Tool Manu 49:998-1007

34. Wang W, Yao P, Wang J, Huang C, Zhu H, Zou B, Liu H, Yan J (2016) Crack-free ductile grinding of fused silica under controllable dry grinding conditions. Int J Mach Tool Manu 109:126-136

35. Kassen G (1969) Beschreibung der elementaren Kinematik des Schleifvorgangs. Dr.-Ing, Dissertation, Aachen, RheinischWestfälische Technische Hochschule Aachen

36. Werner G (1971) Kinematik und Mechanik des Schleifprozesses. Dr.-Ing, Dissertation, Rheinisch-Westfälische Technische Hochschule Aachen

37. Zhang Z, Song Y, Xu C, Guo D (2012) A novel model for undeformed nanometer chips of soft-brittel $\mathrm{HgCdTe}$ films induced by ultrafine diamond grits. Scr Mater 67:197-200

38. Zhang Z, Huo F, Zhang X, Guo D (2012) Fabrication and size prediction of crystalline nanoparticles of silicon induced by nanogrinding with ultrafine diamond grits. Scr Mater 67:657-660

39. Zhang ZY, Huo YX, Guo DM (2013) A model for nanogrinding based on direct evidence of ground chips of silicon wafers. Sci China Technol Sci 56:2099-2108

40. Zhang Z, Wang B, Kang R, Zhang B, Guo D (2015) Changes in surface layer of silicon wafers from diamond scratching. CIRP Ann Manuf Technol 64:349-352
41. Wu H, Melkote SN (2012) Study of ductile-to-brittle transition in single grit diamond scribing of silicon: application to wire sawing of silicon wafers. J Eng Mater Technol 134(4):041011

42. Lee SH (2012) Analysis of ductile mode and brittle transition of AFM nanomachining of silicon. Int J Mach Tools Manuf 61:71-79

43. Tang FZ; Zhang LC (2014) Subsurface nanocracking in monocrystalline $\mathrm{Si}\left(\begin{array}{lll}0 & 0 & 1\end{array}\right)$ induced by nanoscratching. Engineering Fracture Mechanics 124-125: 262-271, - +9

44. Göttsching TC (2017) Schleifen von aluminiumhaltigem UHCStahl. Dissertation, Hannover, Leibniz Universität Hannover, Dr.Ing

45. Denkena B, Grove T, Seiffert F (2015) Mikrogeometrische Eingriffsverhältnisse beim Längsumfangsplanschleifen. Diamond Business 52:62-72

46. Denkena B, Busemann S, Gottwik L, Grove T, Wippermann A (2017) Material removal mechanisms in grinding of mixed oxide ceramics. Procedia CIRP 65:70-77

47. Furrer J, Dunichert P (1974) Vorrichtung zur plötzlichen Schnittunterbrechung. Fertigung 5(3):105-108

48. Buda J, Liptak J (1988) Grinding mechanisms investigation based on winning and evaluation of the chip roots. J Mech Work Technol $17: 157-165$

49. Göttsching TC, Wippermann A, Grove T (2016) Quick stop device to analyze the chip formation mechanisms in face grinding. Prod. Eng Res Devel 1140:221-227

50. Denkena B, Köhler J, Kästner J (2012) Chip formation in grinding an experimental study. Production Engineering Research and Development (WGP) 2(2):107-115

51. Wippermann A (2018) Schleifen von Umwandlungsverstärkter Mischoxidkeramik. Dissertation, Hannover, Leibniz Universität Hannover, Dr.-Ing

52. Gottwik L, Kuntz M, Porporati A, Ehrlich J, Mohrardt A, Friedrich K Zirconium oxide-based composite material. U.S. Patent Application No. 14/422,541, 20.08.2013

53. Kuntz M, Friedrich K, Gottwik L, Morhardt A, Ehrlich J Zirconiabased monophase and multiphase materials. U.S. patent Application No. 14/766,148, 07.02.2014

54. Denkena B, Gottwik L, Grove T, Wippermann A (2017) Temperature and energy partition for grinding of mixed oxide ceramics. Prod Eng 11(4-5):409-417

55. Carslaw HS (1921) Introduction to the mathematical theory of the conduction of heat in solids, vol 2. Macmillan, London

56. Jaeger JC (1942) Moving sources of heat and the temperature of sliding contacts. Proceedings of the Royal Society of London. NSW 76:205-224

57. Carslaw HS, Jaeger JC (1959) Conduction of heat in solids, 2nd edn. Clarendon Press, Oxford

58. Zhu B, Guo C, Sunderland JE, Malkin S (1995) Energy partition to the workpiece for grinding of ceramics. CIRP Ann 44(1):267-271

59. Kohli S, Guo C, Malkin S (1995) Energy partition to the workpiece for grinding with aluminium oxide and CBN abrasive wheels. J Eng ind 117(2): 160-168

60. Guo C, Wu Y, Varghese V, Malkin S (1999) Temperatures and energy partition for grinding with vitrified CBN wheels. CIRP Ann-Manuf Technol 48(1):247-250

61. Malkin S, Guo C (2007) Thermal analysis of grinding. CIRP Ann 56(2):760-782

Publisher's note Springer Nature remains neutral with regard to jurisdictional claims in published maps and institutional affiliations. 